\title{
Proximal ductus arteriosus stenosis after the hybrid stage I procedure in a newborn with hypoplastic left heart syndrome
}

\author{
Maciej Chojnicki, Ireneusz Haponiuk, Mariusz Steffens, Radoslaw Jaworski, Aneta Szofer-Sendrowska, \\ Jacek Juscinski, Ewelina Kwasniak
}

Department of Pediatric Cardiac Surgery, Mikolaj Kopernik Pomeranian Centre of Traumatology, Gdansk, Poland

Postep Kardiol Inter 2013; 9, 2 (32): 187-189

DOI: $10.5114 /$ pwki.2013.35458

\begin{abstract}
We present a case of a severely ill newborn with hypoplastic left heart syndrome after the hybrid stage I procedure, with right systemic ventricle insufficiency due to proximal ductus arteriosus stenosis. The child was successfully treated with percutaneous second PDA stent implantation.
\end{abstract}

Key words: hypoplastic left heart syndrome, hybrid procedures in HLHS, stage I of HLHS treatment, newborn.

\section{Introduction}

The first stage of palliative hybrid treatment of children with congenital heart disease (HLHS hybrid stage I) in the form of hypoplastic left heart syndrome (HLHS) is an alternative to the Norwood procedure [1, 2]. It includes right and left pulmonary artery (RPA and LPA) banding with concomitant persistent arterial duct (PDA) stenting. One of the complications of this form of treatment in children is PDA stenosis [3].

We present a case of a female patient with HLHS after the first stage of hybrid treatment, who presented with deterioration of the systemic right ventricle contractility caused by stenosis in the proximal part of the PDA, which was not covered with the stent.

\section{Case report}

A 2-day neonate with prenatally diagnosed congenital heart disease in the form of hypoplastic left heart syndrome underwent RPA and LPA banding and stent implantation to the PDA as the first stage of the hybrid treatment (HLHS hybrid stage I). Alprostadil (Prostin ${ }^{\circledR}$ ) was discontinued. This was followed by balloon atrioseptostomy. The child was extubated on the second day after the procedure without any complications. A control echocardiographic examination (ECHO) performed routinely after the procedure confirmed the presence of normal right ventricular function, normal tricuspid and pulmonary valve function, free flow through the stent into the descending aorta with an effective backward flow to the ascending aorta and broad inter-atrial communication. From the $7^{\text {th }}$ day after the procedure ECHO studies showed progressive deterioration of the right ventricular function with increasing tricuspid regurgitation and symptoms of stenosis in the proximal part of the PDA, which was confirmed by the diagnostic catheterization (Figure 1). For that reason a second stent was immediately implanted to the stenosed proximal PDA segment using a telescopic technique (Figure 2). Free flow from the pulmonary artery to the aorta was achieved (Figure 3). Control examinations after the procedure demonstrated normalization of the right ventricular and tricuspid valve function, which permitted the child to be discharged from the hospital on the $3^{\text {rd }}$ day after the intervention. A second stage of treatment was performed in the $5^{\text {th }}$ month of the child's life (HLHS comprehensive hybrid stage II, Figure 4). Currently the patient is under ambulatory follow-up and remains in good clinical condition with an observation period of 8 months.

\section{Discussion}

Irrespectively of the treatment modality used ("Norwood" type operation or hybrid treatment) the result of 

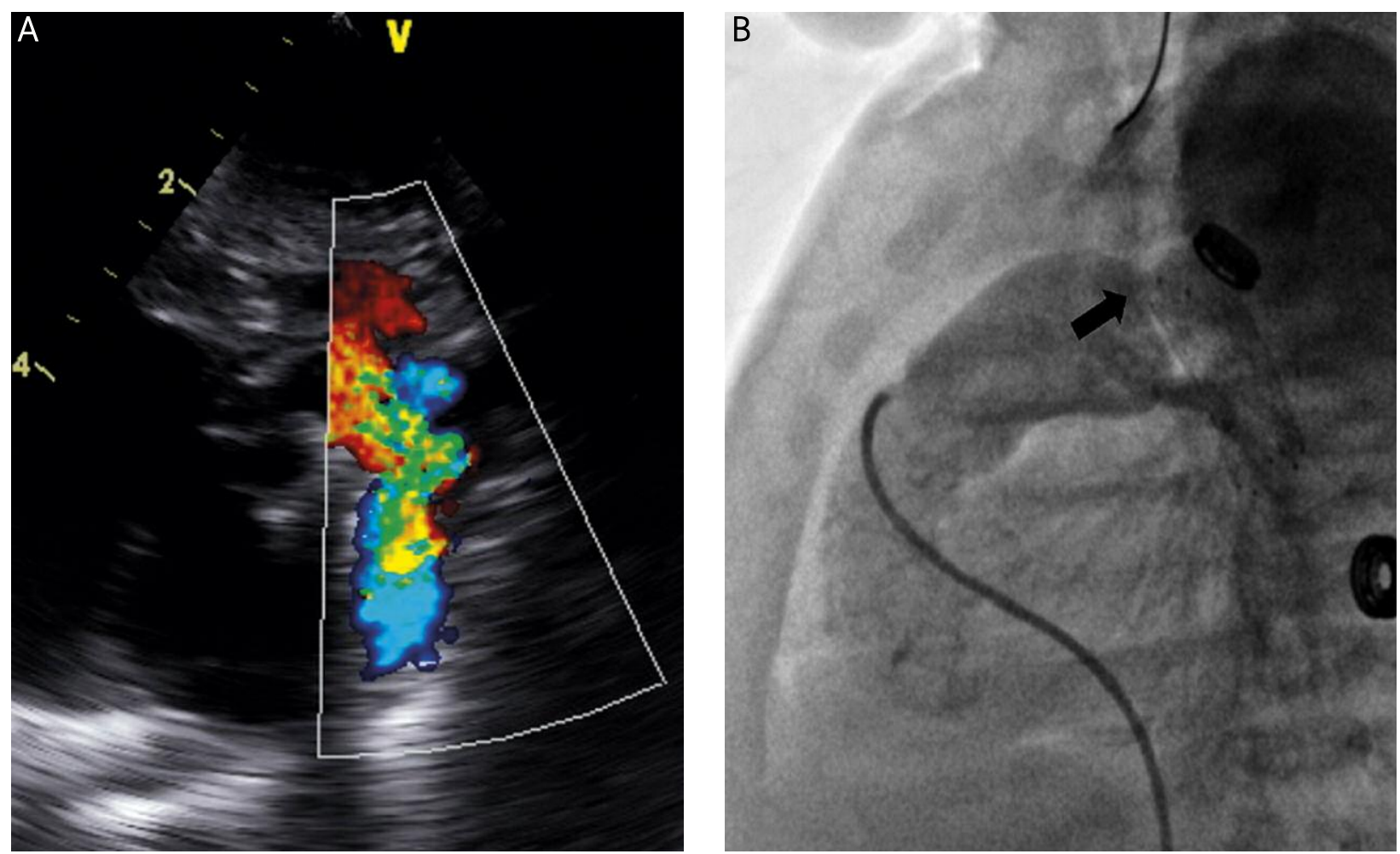

Fig. 1. Proximal ductus arteriosus stenosis after the hybrid stage I procedure in a newborn with hypoplastic left heart syndrome. A - Echocardiography - restrictive blood flow through ductus arteriosus. B - Ventriculography - proximal stenosis of unstented part of the ductus (arrow)
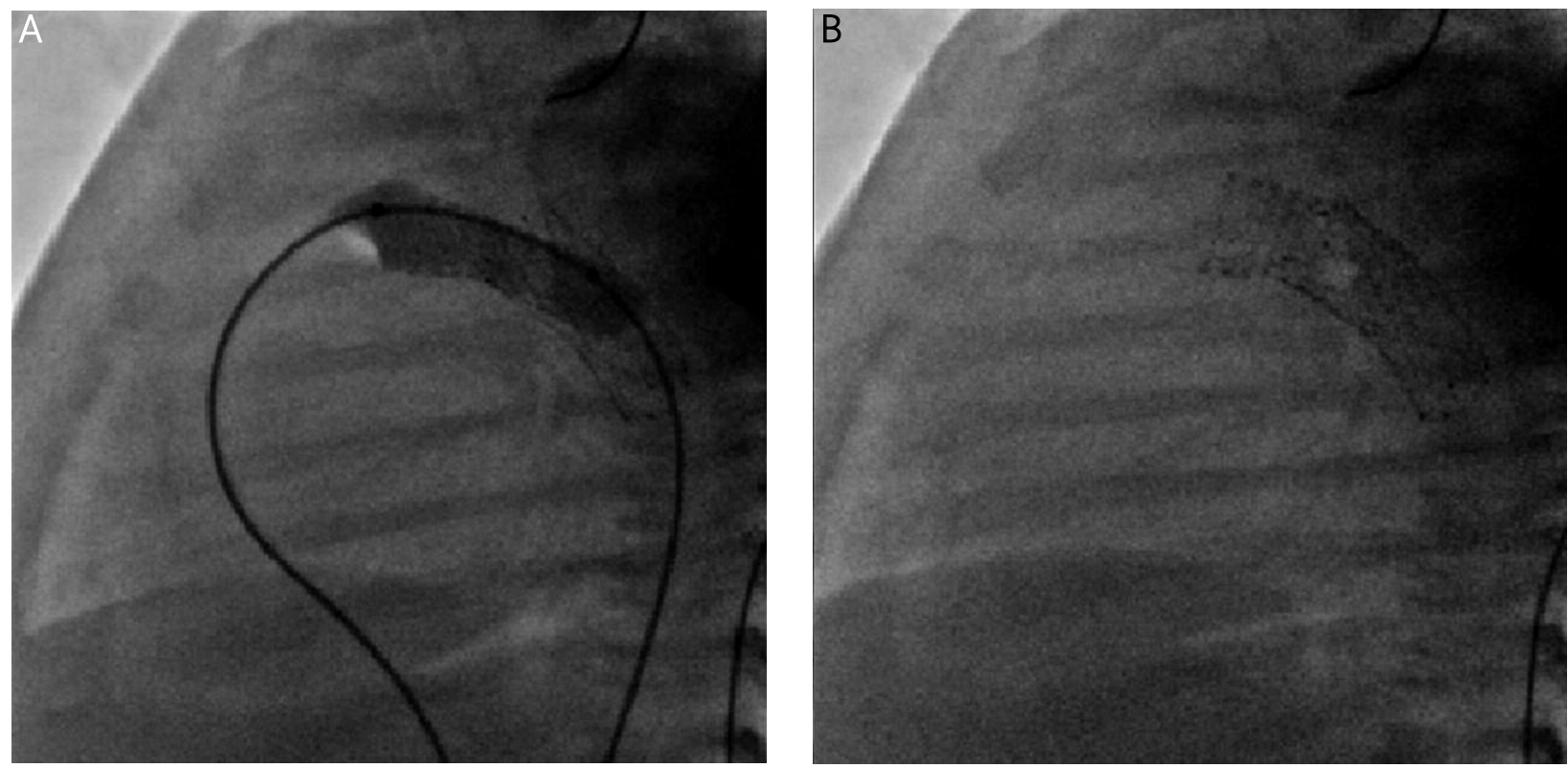

Fig. 2. Cardiac catheterization - lateral view. A - Second stent implantation into ductus arteriosus. B - Post-intervention view

treatment of neonates with HLHS depends on the right ventricular function and on optimal blood distribution to the systemic and pulmonary circulation [4]. Any deterioration of the ventricular function may be catastrophic and should be immediately diagnosed and, if possible, a causative treatment should be performed. Prompt diagnosis and appropriate treatment in the presented case led to normalization of the systemic flow and improvement of the right ventricular function. This led to stabilization of the child's general condition and permitted adequate 


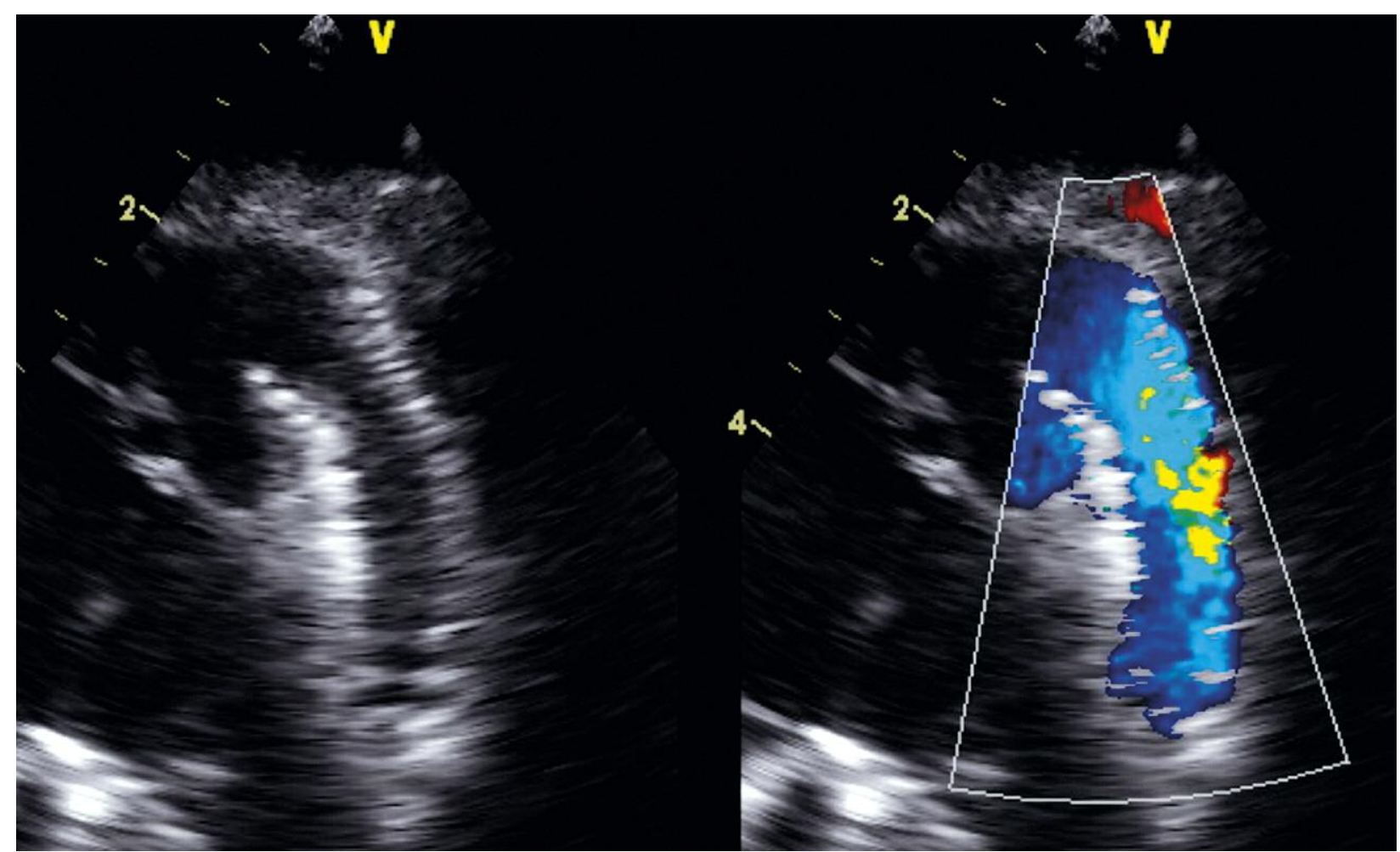

Fig. 3. Control echocardiographic examination after second stent into ductus arteriosus implantation - nonrestrictive blood flow from pulmonary artery into aorta

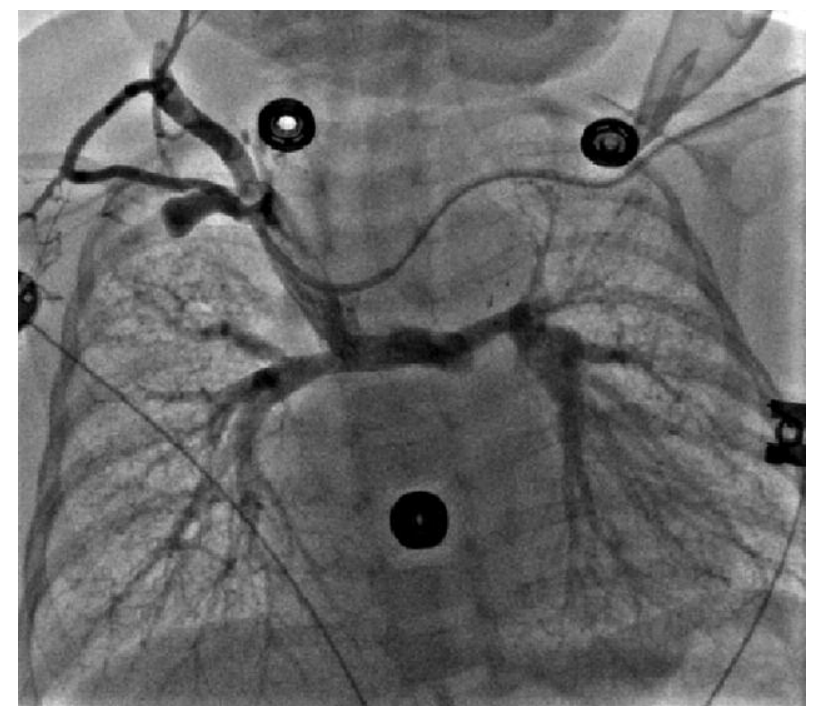

Fig. 4. Phlebography - status after HLHS comprehensive hybrid stage II. Antero-posterior view; contrast infusion through vena subclavia sinistra; opacification of both pulmonary arteries through Glenn anastomosis

preparation of the child for the second stage of HLHS treatment - the HLHS comprehensive hybrid stage II. Hybrid treatment consisting of classic cardio-surgical methods and interventional cardiology techniques is a modern, alternative form of treatment due to reduction of potential side effects of both methods used individually, particularly in patients at the highest risk [5-7].

\section{References}

1. Egan MJ, Trask AJ, Baker PB, et al. Histopathologic evaluation of patent ductus arteriosus stents after hybrid stage I palliation. Pediatr Cardiol 2011; 32: 413-417.

2. Galantowicz M, Cheatham JP. Lessons learned from the development of a new hybrid strategy for the management of hypoplastic left heart syndrome. Pediatr Cardiol 2005; 26: 190-199.

3. Nadorlik HA, Egan MJ, Hill SL, et al. Predictors of ductus arteriosus in-stent stenosis in the hybrid approach to hypoplastic left heart syndrome. Pediatr Cardiol 2013; 34: 656-660.

4. Barron DJ, Kilby MD, Davies B, et al. Hypoplastic left heart syndrome. Lancet 2009; 374: 551-564.

5. Haponiuk I, Chojnicki M, Jaworski R, et al. Delayed closure of multiple muscular ventricular septal defects in an infant after coarctation repair and a hybrid procedure - a case report. Heart Surg Forum 2011; 14: E67-E69.

6. Sroka M, Haponiuk I, Chojnicki M, et al. Cardiovascular hybrid procedure in severe congenital diaphragmatic hernia with significant left heart hypoplasia. Eur J Cardiothorac Surg 2012; 42: 185-187.

7. Haponiuk I, Chojnicki M, Jaworski R, et al. Miniinvasive hybrid closure of multiple muscular ventricular septal defects in a premature infant with novel use of Amplatzer Duct Occluder II - a case report. Videosurgery Miniinv 2011; 6: 33-36. 